\title{
AVALIAÇÃO DA DEGRADAÇÃO AMBIENTAL A PARTIR DA PRÁTICA DA CULTURA DO FEIJÃO NO MUNICÍPIO DE TAVARES-PB
}

\author{
D. D. E. SILVA ${ }^{1 *}$, F. T. A. FELIZMINO², M. G. OLIVEIRA ${ }^{2}$ \\ ${ }^{1}$ Universidade Federal de Campina Grande \\ ${ }^{2}$ Instituto Federal da Paraíba \\ dalvaestevamifpb@gmail.com*
}

Artigo submetido em março/2014 e aceito em dezembro/2015

DOI: $10.15628 /$ holos.2015.2063

\section{RESUMO}

A degradação ambiental é um fator preocupante principalmente na região Nordeste. Nessa região, as causas da degradação são diversas, sendo intensificadas pela ação do clima. As atividades antrópicas causam pressão sobre os recursos naturais, destacando-se a agricultura que provoca desequilíbrio nos ecossistemas como: perda da biodiversidade, modificação no ciclo hidrológico, entre outros. Além disso, com a ocorrência das secas, há diminuição da vegetação, empobrecimento do solo e perda da biodiversidade pelas queimadas. Neste sentido, este trabalho tem como objetivo analisar a degradação ambiental a partir da prática do cultivo do feijão no município de Tavares, Paraíba. A metodologia utilizada envolveu visitas in loco, com registro fotográfico da área de estudo, no sentido de identificar a ação antrópica sobre o ambiente, bem como a aplicação de questionários. Observou-se que o desmatamento e as queimadas são as técnicas praticadas pelos agricultores que geram mais impactos negativos e que o preparo do solo é realizado de forma inadequada contribuindo para a erosão e lixiviação. Além disso, observou-se a utilização de agrotóxicos nas lavouras, o que vem contribuindo para a poluição do solo e do lençol freático. Ficou evidenciada a necessidade de mudança nas técnicas de preparação e conservação do solo, a fim de minimizar os impactos negativos observados. Destaca-se, portanto, a necessidade de mudanças de práticas culturais para que essa realidade seja modificada e os locais degradados sejam recuperados.

PALAVRAS-CHAVE: práticas agrícolas, feijão, Tavares (PB).

\section{EVALUATION OF ENVIRONMENTAL DEGRADATION FROM THE PRACTICE OF THE CULTURE BEAN IN THE CITY OF TAVARES-PB}

\begin{abstract}
Environmental degradation is a concern especially in the Northeast. In this region, the causes of degradation are diverse, being intensified by climate action. Anthropic activities cause pressure on natural resources, especially agriculture which causes imbalance in the ecosystems as loss of biodiversity, changes in hydrological cycle, among others. Moreover, with the occurrence of droughts, there is a decrease of vegetation, soil depletion and biodiversity loss by fires. Thus, this study aims to analyze the environmental degradation from the practice of growing beans in the city of Tavares, Paraíba. The methodology involved site visits, with photographic record of the study area, in order to identify the human action on the
\end{abstract}

environment, as well as questionnaires. It was observed that deforestation and burning are techniques practiced by farmers who generate more negative impacts and that soil preparation is performed improperly contributing to erosion and leaching. Furthermore, we observed the use of pesticides on crops, which has contributed to the pollution of soil and groundwater. Evidence of the need for change in preparation techniques and soil conservation in order to minimize negative impacts observed. It is noteworthy, therefore, the need to change habits so that this reality is modified and degraded sites are recovered.

KEYWORDS: agricultural practices, beans, Tavares (PB). 


\section{INTRODUÇÃO}

A degradação ambiental crescente é um fator preocupante, resultante da ação antrópica negativa, que altera e modifica o meio ambiente. Dessa forma, a agricultura contribui com o empobrecimento do solo através das atividades agrícolas exercidas, com isso modificando suas características químicas, físicas e biológicas.

A degradação dos solos é a "alteração das propriedades do solo que acarreta efeitos negativos sobre uma ou várias funções do solo, a saúde humana ou o meio ambiente" (ISO 110741: 1996 apud SÁNCHES, 2006, p. 16). Sendo os principais fatores da degradação do solo, o desmatamento, a agricultura, o superpastoreio, entre outros, constituindo em prejuízos econômicos, sociais e ambientais. Apesar dos impactos negativos provocados pela agropecuária, essa atividade é de extrema importância para a economia e a sociedade, fornecendo alimentos para a população. No entanto, se faz necessário o planejamento racional para o uso das terras e uso sustentável dos recursos naturais em conformidade com cada atividade.

Segundo Dent; Young (1993) apud SABOYA et al., (2008, p. 9) afirmam que:

A falta de um planejamento racional de uso da terra, seja pela falta de conhecimento, seja pela necessidade dos agricultores, tem promovido diversos impactos negativos, muitas vezes chegando a limites críticos em determinadas regiões, resultando em degradação ambiental e redução da qualidade de vida, não só para a comunidade rural, mas também para toda população.

A ação antrópica negativa tem gerado impactos ao meio ambiente, ocasionando em perda da biodiversidade e da qualidade de vida da população, seja rural ou urbana. Sendo a falta de planejamento ou conhecimento um problema, principalmente na região Nordeste onde a agricultura é realizada em pequenas áreas (sequeiro). Dentre as técnicas mais utilizadas pelos agricultores destacam-se o desmatamento, as queimadas e o preparo do solo, expondo o solo aos fatores climáticos intensificando a degradação (SILVA, 2012).

Neste sentido, o artigo 225, caput, da Constituição Federal/1988, diz que: "Todos têm direito ao meio ambiente ecologicamente equilibrado, bem de uso comum do povo e essencial à sadia qualidade de vida, impondo-se ao poder público e à coletividade o dever de defendê-lo e preservá-lo para as presentes e futuras gerações" (SIQUEIRA, 2008, p. 30). Observa-se que mesmo com o avanço das leis ambientais e da rigorosidade em muitos casos a legislação é descumprida e a degradação do meio ambiente é crescente.

O município de Tavares (PB), localizado na Microrregião Serra do Teixeira, tem como tradição a prática do cultivo do feijão, atividade agrícola passada de geração para geração, que há anos vem contribuindo para a degradação ambiental dos solos. A expansão da agropecuária e o uso de técnicas agrícolas para a preparação da terra como (queimadas, desmatamento e preparo indevido do solo) são as mais impactantes na região, que provocam modificações severas no solo, afetando suas características básicas, que são significativas para o desenvolvimento da flora e a preservação dos corpos hídricos.

Conforme exposto, a degradação se tornou um problema. Essas atividades são realizadas no período que antecede o preparo do solo, sendo o desmatamento realizado durante todo o ano para a exploração madeireira. A resultante da degradação são as áreas com indícios da 
desertificação que se fazem presentes no município. Além dos impactos gerados pela ação antrópica, as áreas agricultáveis diminuíram ao longo dos anos, devido à migração dos agricultores para o corte da cana de açúcar, migração esta realizada no período do plantio.

Esse trabalho teve como objetivo analisar a degradação ambiental a partir da prática do cultivo do feijão no município de Tavares (PB). Sendo realizadas visitas in loco nos anos de 2011 e 2012 com o intuito de observar a área e registrar com fotografias, foram aplicados 100 questionários semi-estruturados de forma direta aos chefes das famílias.

\section{FUNDAMENTAÇÃO TEÓRICA}

A modificação dos sistemas naturais são decorrentes das atividades antrópicas que provocam alterações na biota. No semiárido nordestino as práticas agrícolas intensificam a degradação ambiental, pricipalmente dos solos. Dessa forma, a degradação tem crescido, fator que provoca a desertificação que é um processo ocasionado pela ação antrópica ou por fatores naturais.

\subsection{Degradação ambiental}

De acordo com a Política Nacional do Meio Ambiente (Lei Federal n 6.938/81), degradação ambiental é qualquer "alteração adversa das características do meio ambiente" (art.3o, inciso II), neste sentido observa-se que trata de um "conceito amplo que abrange vários casos como prejuízo à saúde, ao bem-estar das pessoas, às atividades sociais e econômicas, à biosfera, etc" (LIMA et al., 2008c, p. 1).

O desenvolvimento das atividades antrópicas negativas, exerce forte pressão sobre o meio ambiente provocando consequências irreversíveis aos recursos naturais. Assim "degradação ambiental pode ser conceituada como qualquer alteração adversa dos processos, funções ou componentes ambientais, ou como uma alteração adversa da qualidade ambiental" (SÁNCHEZ, 2008 apud LIMA et al., 2008c, p. 1).

A degradação ambiental ocorre principalmente pela ação antrópica que esgota os recursos naturais. Dessa forma, a prática da agricultura atualmente é uma das principais causas de degradação do solo na região Nordeste. Sobre isso, Silva e Corrêa (2007, p. 172) afirmam que:

No Semi-árido nordestino, a sucessão temporal de modos de produção incompatíveis com a sustentabilidade dos sistemas físicos de superfície terrestre resulta em uma série de problemas ambientais que são visualizados e sentidos contemporaneamente, e que representam a totalidade da degradação ambiental, advinda de usos pretéritos e atuais.

Neste sentido "áreas degradadas são aquelas caracterizadas por solos empobrecidos e erodidos, instabilidade hidrológica, produtividade primária e diversidade biológica reduzida" (PARROTA, 1992, apud KOBIYAMA; MINELLA; FABRIS, 2001, p. 1).

As técnicas agrícolas usadas pelos agricultores fazem com que os solos esgotem suas reservas de nutrientes, com isso a reposição de nutrientes se faz necessária. Wadt et al., (2003, p. 12) definem a degradação agrícola como sendo: 
[...] o processo inicial no qual o sistema apresenta perda da produtividade econômica, com desequilíbrio pela ausência de ações no sentido de mantê-lo no ponto ideal de controle das ervas daninhas e de agentes bióticos adversos (fitopatógenos, pragas), resultando em menor produção da cultura principal. Nessa situação, não há necessariamente uma perda da capacidade do solo em sustentar o acúmulo de biomassa, porém, haverá perdas devido à redução do potencial de produção das plantas cultivadas.

As técnicas inadequadas provocam uma série de impactos que muitas vezes são visíveis na paisagem, principalmente nos solos, que se encontram cansados, e desprovidos de vegetação e nutrientes.

Entretanto, quando o solo é desprovido de sua vegetação ou cultivado fica sujeito a uma série de fatores degradantes, visto que os cuidados com o preparo e manuseio do solo são mínimos, motivados certamente pela falta de maiores informações para os agentes produtivos e pela falta de assistência técnica direta, que acabam por gerar baixos níveis tecnológicos de produção.

As práticas de exploração do solo e dos demais recursos naturais promovem mudanças na ambiência e quando não são observadas as práticas sustentáveis a situação pode tornar-se impactante, dessa forma as "[...] atividades agrícolas provocam impactos sobre o ambiente, tais como desmatamentos e expansão da fronteira agrícola, queimadas em pastagens e florestas, poluição por dejetos animais e agrotóxicos, erosão e degradação de solos e contaminação das águas" (FIRMINO; FONSECA, 2008, p. 4).

Tais impactos provocam danos que muitas vezes podem ser irreversíveis, como é o caso da desertificação. Neste sentido é possível observar indícios da desertificação em áreas cultivadas há décadas no município, processo resultante das práticas agrícolas inadequadas. Outro fator evidenciado é o problema da erosão do solo na área rural do município, que é provocada pela degradação do solo (desmatamento, queimadas e preparo inadequado do solo), pela ação das chuvas (erosão hídrica) e dos ventos (erosão eólica), que evoluem para a formação de voçorocas. A erosão laminar também está presente sendo uma problemática nessa região.

Na região Nordeste a degradação é intensa devido às atividades agrícolas utilizadas na agricultura, nessas áreas a grande maioria dos agricultores não pratica o pousio para que os solos recuperem naturamente seus nutrientes, sobre isso Lepsch $(1976$, p. 138) assevera que:

Em condições normais, sem a influência do homem, os restos vegetais são devolvidos a terra pela sua queda e decomposição. Portanto, sempre que o agricultor retira da terra os produtos vegetais, ele exporta certa quantidade de elementos nutritivos essenciais às plantas. Essas retiradas são como saques feitos em um depósito de capacidade limitada e, quando continuamente repetido sem reposição equivalente redundam no esgotamento progressivo das terras. Alguns tipos de solos têm grande reserva mineral, podendo sustentar por vários anos uma agricultura, sem reposição dos nutrientes pela aplicação de fertilizantes. Outros, ao contrário, dispõem de uma reserva pequena, podendo sustentar a agricultura por um período de apenas dois ou três anos, ou são naturalmente tão pobres que, se não foram devidamente adubados, desde o início de seu cultivo, nada produzirão. 
O esgotamento dos nutrientes pela prática da agricultura é preocupante, pois muitos agricultores desconhecem as técnicas que podem contribuir para reverter esse quadro, que pode levar a desertificação". "Agricultores e pequenos criadores dotados de pequenas posses materiais podem chegar a contribuir para o avanço da desertificação quando levam ao limite a utilização dos escassos recursos que mobilizam para produzir seu sustento" (LIMA et al., 2004a. p. 36).

A falta de conhecimento sobre as questões ambientais contribuem para que esse quadro permaneça e vários fatores facilitam o depauperamento do meio ambiente. Nesse mesmo sentido Lima (2006b, p. 1) afirma que:

Existem vários fatores econômicos, culturais e sociais associados à degradação do solo. Porém um dos aspectos que contribui para a degradação dos solos é o desconhecimento sobre este componente do ambiente, e sua importância. Por outro lado, a conservação do solo pode ser estimulado com o acesso ao conhecimento sobre este componente ambiental, e sua importância.

Dessa forma é necessário informar, capacitar e sensibilizar os agricultores sobre tais problemas, pois o conhecimento da problemática pode contribuir para a diminuição de tal problema. Entretanto Wadt et al., (2003, p. 12) define como processo final a degradação biológica que ocorre após a degradação agrícola.

\footnotetext{
A degradação biológica consiste no processo final no qual há uma intensa diminuição da capacidade de produção da biomassa vegetal e é provocada, primariamente, pela degradação dos solos, ocasionada por diferentes processos que conduzem à perda de nutrientes e da matéria orgânica, e ao aumento da acidez ou da compactação. É nessa fase que os processos erosivos tornam-se evidentes.
}

Com a perda dos nutrientes e da matéria orgânica, o solo fica propenso à erosão, a acidez e a salinização. Com isso "os solos com culturas anuais, como milho, algodão e soja, estão mais expostos à erosão que os solos cultivados com plantas perenes ou semiperenes, como o café, canade-açúcar, laranja, seringueira e cacaueiro" (LEPSCH, 1976, p. 142). No caso da cultura do feijão que é uma cultura anual os solos ficam mais expostos e com maiores possibilidades de tornaremse erodidos.

\section{ASPECTOS METODOLÓGICOS}

“O município de Tavares está localizado na região Oeste do Estado da Paraíba, limitandose a Oeste com Princesa Isabel, a Norte com Nova Olinda, a Leste com Juru e a Sul com a localidade de Quixaba em Pernambuco" (BELTRÃO et al., 2005, p. 2). Possui uma população de 14.103 habitantes e ocupa uma área de $237,329 \mathrm{~km}^{2}$. Sua densidade demográfica é de $59,42 \mathrm{hab} / \mathrm{km}^{2}$ (IBGE, 2010). A sede municipal apresenta uma altitude de $705 \mathrm{~m}$ e coordenadas geográficas de $37^{\circ}$ $52^{\prime} 40^{\prime \prime}$ O e $07^{\circ} 38^{\prime} 09^{\prime \prime}$ S (BELTRÃO et al., 2005, p. 2).

\footnotetext{
${ }^{1}$ Processo de destruição do potencial de produção pela ação antrópica.
} 


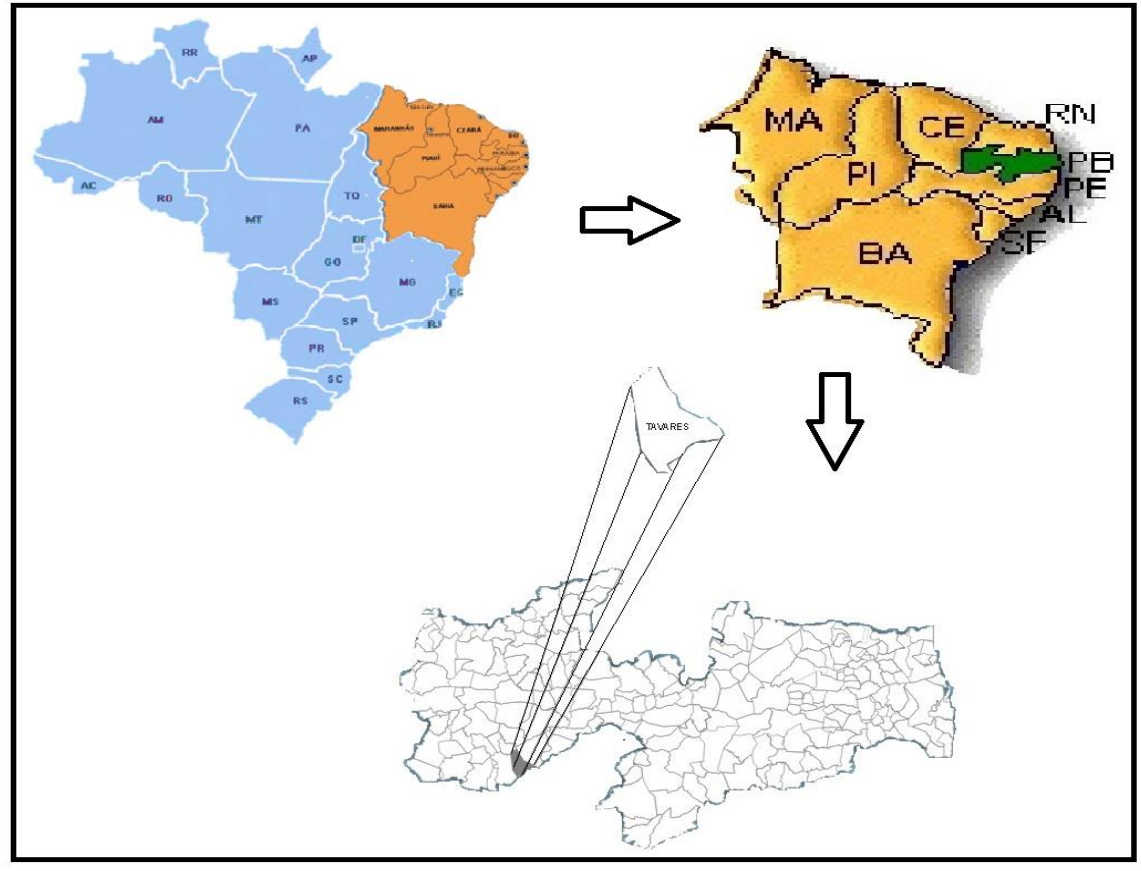

Figura 1- Localização do município de Tavares. Fonte: Adaptado da CPMR, 2005.

No município, a prática da agricultura é tradicional, bem como as técnicas agrícolas utilizadas pelo modelo de produção da agricultura familiar. Outro fator é a migração que ocorre anualmente principalmente para as regiões Sul e Sudeste do Brasil, acarretando na redução significativa das atividades agrícolas em termos de áreas plantadas, porém, apesar dessa diminuição, observou-se que essas atividades continuam sendo exercidas pelas esposas e filhos pequenos que permanecem no município.

\subsection{Procedimentos Metodológicos}

A pesquisa apresenta uma abordagem qualitativa dos aspectos da área de estudo. Quanto aos seus objetivos e procedimentos é classificada, como exploratória e participante. $O$ trabalho foi iniciado com uma pesquisa bibliográfica em periódicos especializados e livros, com a finalidade de construir o embasamento teórico e empírico da pesquisa.

Para a coleta dos dados utilizou-se a observação direta e entrevistas, sendo estas realizadas em diversas áreas do município de Tavares. Segundo Thiollent (1982), "na entrevista guiada, o pesquisador conhece os aspectos que deseja pesquisar e, com base neles, formula pontos para tratar na entrevista, onde, o entrevistado tem a liberdade para expressar-se como quiser". A realização das entrevistas teve como objetivo coletar dados referentes às atividades realizadas pelos agricultores. Os dados foram analisados à medida que foram sendo coletados.

Nesta fase, foi realizado um registro fotográfico para visualização da área de estudo, fase importante para registrar os aspectos analisados durante a pesquisa, bem como, a degradação ambiental ocasionada pelas atividades agrícolas.

A amostra utilizada para o trabalho de campo compreendeu a aplicação de 100 questionários/entrevistas aplicados aleatoriamente em diferentes áreas do município, precisamente 33 sítios da zona rural, buscando coletar informações referentes aos anos de 2010, 
2011 e 2012, sendo entrevistados exclusivamente os agentes produtivos, ou seja, o responsável pela família (chefe de família).

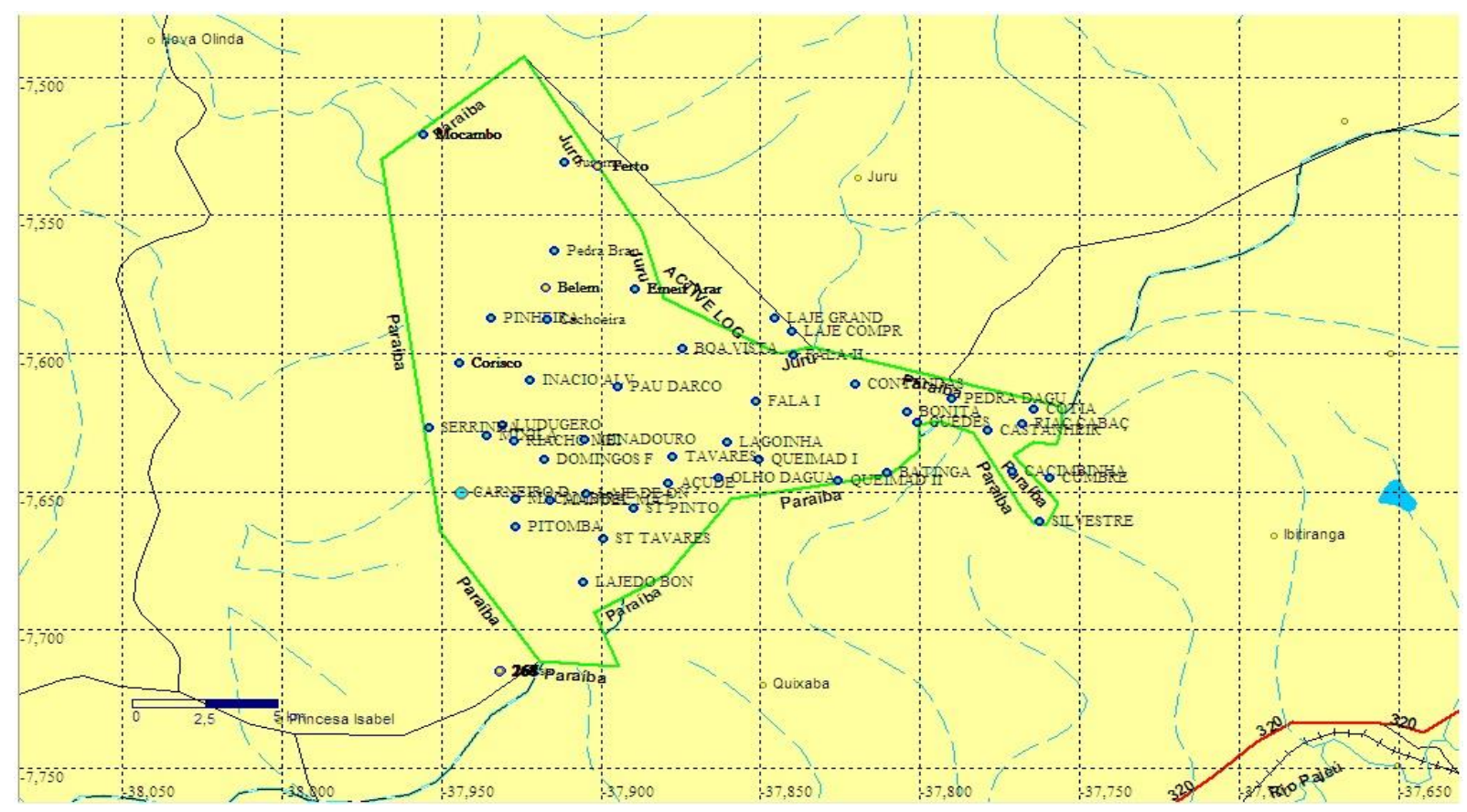

Figura 2 - Mapa do município de Tavares, localização das áreas onde foram aplicados os questionários/entrevistas.

Fonte: EMATER - Tavares/PB (2012).

O período de aplicação dos questionários estendeu-se de 18 de julho a 14 de setembro de 2012, aplicados em diferentes áreas representadas pelos pontos azuis no mapa acima. Abrangendo praticamente todo o município a fim de coletar os dados. Para construção dos gráficos utilizou-se o Software Excel.

Utilizou-se ainda o GPS Etrex Legend Garmim para localização da latitude e longitude dos pontos onde foram realizadas as entrevistas. Neste mesmo sentido utilizou-se o programa GPS TrackMaker PRO 4.8 para fazer o mapeamento dos trabalhos nas áreas previamente delimitadas.

\section{RESULTADOS E DISCUSSÃO}

\subsection{A agricultura no município de Tavares, PB}

A agricultura no município de Tavares atingiu seu ápice entre as décadas de 70 e 80 . Nesse período a cultura de destaque na localidade era o feijão, motivo pelo qual ficou conhecida como -Terra do feijão, chegando a exportar sua produção para outros estados como o Pernambuco e o Rio Grande do Norte, abastecendo o comércio local e o regional.

Entretanto, devido às práticas agrícolas inadequadas, a falta de manejo e a migração intensa nessa região a produção diminuiu significativamente. Segundo a Companhia Nacional de Abastecimento $(C O N A B, 2011)$ a produção vem diminuindo devido à falta de mão-de-obra, pois os filhos dos agricultores familiares estão se deslocando para trabalharem no corte de cana-de-açúcar no Sudeste do país. Neste contexto, a agricultura é praticada pelos poucos agricultores que permanecem no município, pelas esposas e filhos pequenos. 
Mesmo com a diminuição da área plantada e da redução da produção agrícola, os poucos agricultores tem feito o uso de práticas de manejo do solo inadequadas o que tem contribuído para o aumento da degradação ambiental.

Os principais fatores de degradação ambiental observados no município são expressos no quadro 1:

Quadro 1 - Práticas agrícolas inadequadas (enquanto fatores de desagregação ambiental) e consequentes impactos.

\begin{tabular}{|l|l|}
\hline \multicolumn{1}{|c|}{ PRÁTICAS AGRÍCOLAS INADEQUADAS } & \multicolumn{1}{c|}{ IMPACTO AMBIENTAL NEGATIVO } \\
\hline Desmatamento e/ou Brocas ${ }^{2}$ & $\begin{array}{l}\text { Exposição do solo aos fatores climáticos (vento, } \\
\text { insolação e chuvas), erosão hídrica, extinção de espécies } \\
\text { da fauna e da flora. }\end{array}$ \\
\hline Queimadas & $\begin{array}{l}\text { Emissão de gases para a atmosfera, esterilização dos } \\
\text { solos, destruição dos ecossistemas, morte dos } \\
\text { microrganismos fundamentais para o solo, perda dos } \\
\text { minerais, destruição da fauna e da flora e o } \\
\text { empobrecimento do solo. }\end{array}$ \\
\hline Preparo do Solo & $\begin{array}{l}\text { Erosão do solo, perda da matéria orgânica, lixiviação, } \\
\text { desnivelamento do solo entre outros. }\end{array}$ \\
\hline Preparo Semi Direto (SPD) & $\begin{array}{l}\text { Compactação dos solos, impermeabilização da água } \\
\text { chuva, erosão superficial. }\end{array}$ \\
\hline
\end{tabular}

Fonte: A autora, 2012.

Esses fatores contribuem com a crescente degradação do meio ambiente. "O impacto imediato dessa situação é o comprometimento dos processos hidrológicos que determinam os ciclos de cheia e seca, em grande parte responsáveis por toda a riqueza biológica de uma região e a perda de biodiversidade [...]" (CUNHA, 2007, p. 1). Dessa forma, o ciclo hidrológico pode ser alterado nessa região, agravando o regime hídrico que castiga o sertanejo.

\subsection{Técnicas agrícolas utilizadas no cultivo do feijão}

As técnicas mais utilizadas pelos agricultores no município de Tavares são: Desmatamento, queimadas, preparo do solo. Essas técnicas são nocivas ao meio ambiente, provocando impactos ambientais e intensificando a degradação ambiental em toda a área do município.

\subsubsection{Desmatamento}

O desmatamento no município é realizado principalmente para a expansão da agropecuária, fabricação de carvão, comercialização da lenha, construção de cercas entre outros (Figuras 3 e 4). Sendo essa atividade maior no período que antecede o preparo do solo. Esse modelo extrativista provoca a aceleração do processo de erosão e infertilidade do solo, além disso, afeta a qualidade da água diminuindo os cursos de riachos e córregos.

\footnotetext{
${ }^{2}$ Desmatamento realizado com o objetivo de limpar o terreno em áreas que já foram desmatadas.
} 

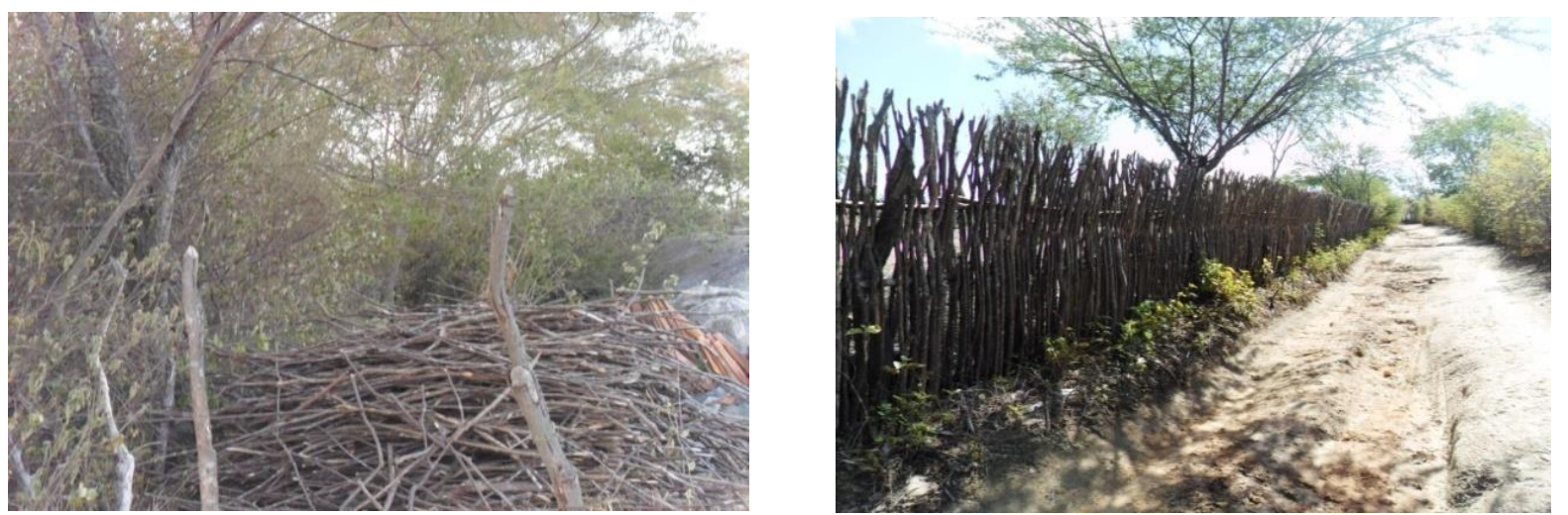

Figuras 3 e 4 - Respectivamente: Utilização de lenha retirada da mata para produção de Carvão e estacas (cercas). St. Lagoinha, município de Tavares - PB.

Fonte: Arquivo da pesquisadora (2012).

Essa prática provoca também danos negativos à fauna. Este fato é preocupante, visto que as práticas agrícolas inadequadas fazem parte da cultura agrícola regional. No entanto, o desmatamento provoca impactos ambientais que causam desequilíbrio à biodiversidade local.

O desmatamento é comum, sendo realizado em todas as áreas do município com destaque para os topos de serras e encostas principalmente na porção Norte do município. Sendo essa uma prática danosa ao meio ambiente praticada pela maioria dos agricultores como mostra a figura 5 .

DESMATAMENTO

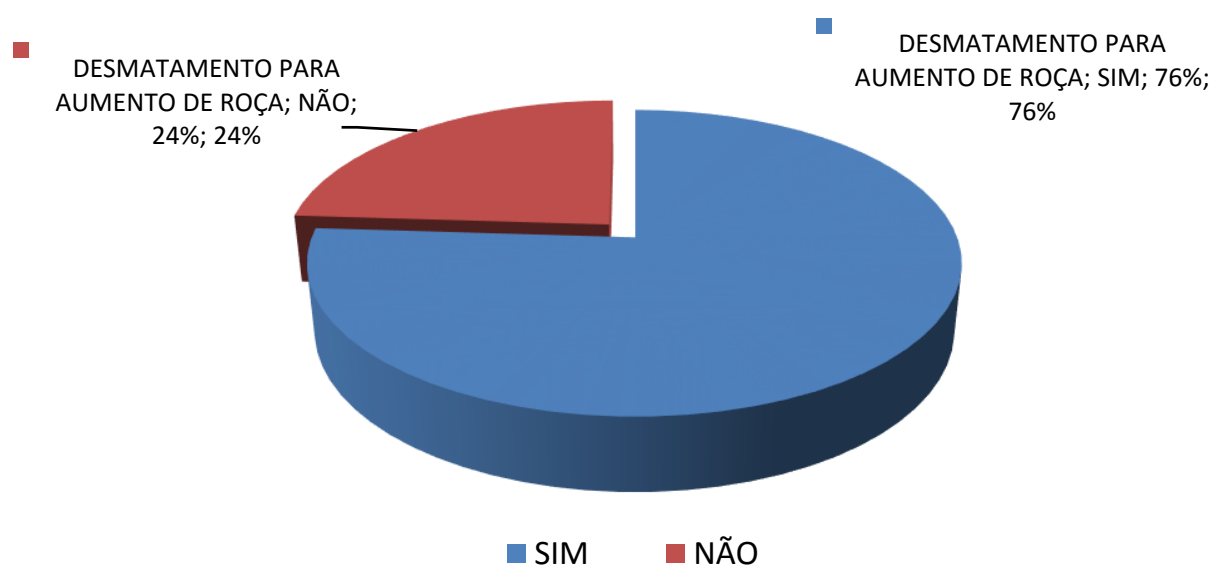

Figura 5 - Desmatamento realizado pelos agricultores abordados na pesquisa. Fonte: A autora (2012).

A figura 5 mostra que $76 \%$ dos agricultores desmata a caatinga para aumentar e/ou limpar a roça, além disso, o desmate também é realizado para fins de fabricação de carvão e comercialização da lenha. Sendo uma pequena minoria que corresponde a $24 \%$ afirma não desmatar, só realiza a broca antes do preparo do solo. Observou-se que ao longo dos anos as matas diminuiram e atualmente existem resquicios de matas, ocasionando em impactos visíveis na paisagem (Figuras 6 e 7). Na área existem indícios de desertificação, sendo esta ação motivada pela ação antrópica. 

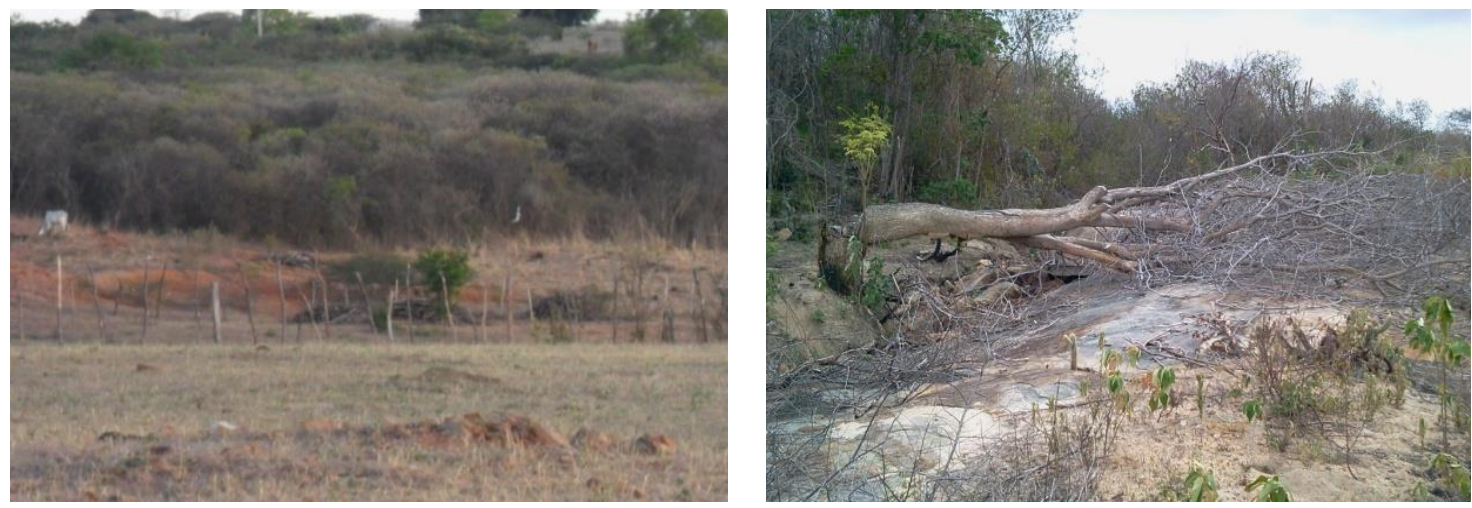

Figuras 6 e 7 - Respectivamente: Área desmatada para a prática da agropecuária e desmatamento de árvores de médio e pequeno porte para a expansão da agropecuária.

Fonte: Arquivo da pesquisadora (2012).

Nos locais onde já houve o desmatamento, a vegetação predominante é secundária, dessa forma os agricultores realizam a broca ou a limpa do terreno (Figura 8), que constitui no roçado da vegetação de pequeno porte (capoeiras). Após a broca ou a limpa, os agricultores preparam as "coivaras" que são restos de vegetação provenientes do roçado, para serem queimados (Figura 9).
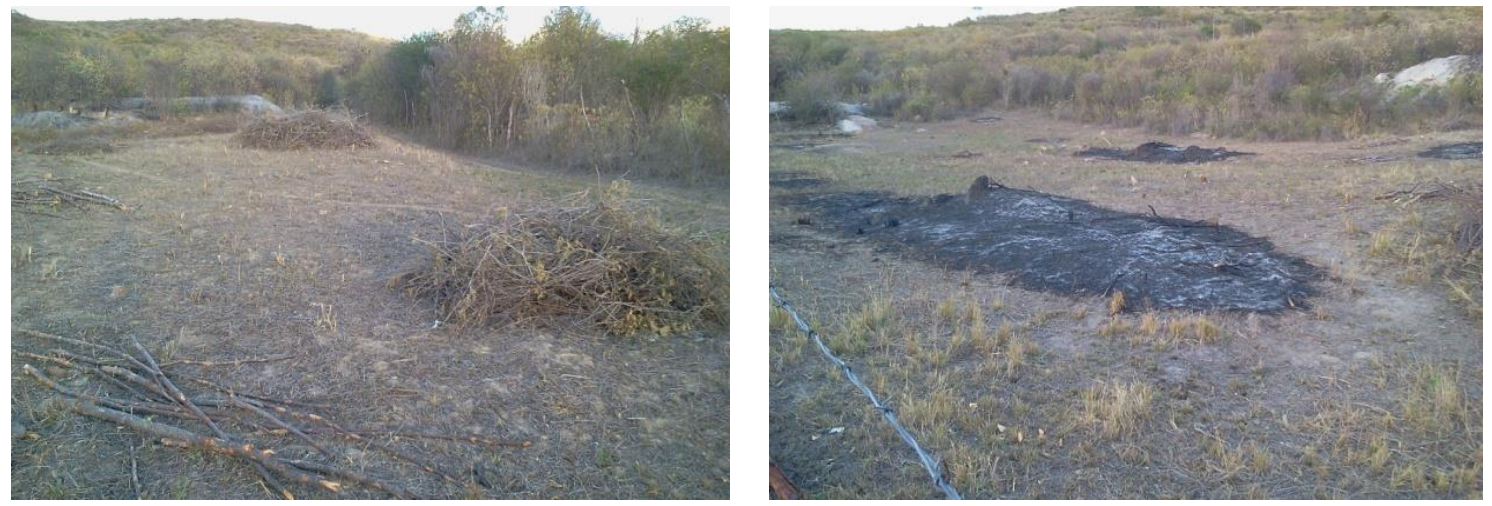

Figuras 8 e 9 - Respectivamente: Coivaras preparadas para a queima e pós-queima. Fonte: Arquivo da pesquisadora (2012).

Essa é uma prática danosa ao meio ambiente, no entanto as figuras 5 e 6 mostram a forma mais adequada de fazer as queimadas, pois não há a queima total do terreno, mesmo assim essa prática provoca impactos.

Entre os principais fatores de degradação ambiental observados, destacam-se os descritos no quadro 2:

Quadro 2 - Impactos ambientais provenientes do desmatamento.

\begin{tabular}{|c|l|}
\hline DESMATAMENTO & \multicolumn{1}{c|}{ IMPACTO AMBIENTAL NEGATIVO } \\
\hline Fauna & $\begin{array}{l}\text { Desaparecimento de espécies desconhecidas do Bioma Caatinga pelo homem, bem como das } \\
\text { ameaçadas de extinção. }\end{array}$ \\
\hline Flora & Extinção de espécies floristicas não catalogadas e desconhecidas. \\
\hline Solos & $\begin{array}{l}\text { Exposição da cobertura do solo aos fatores ambientais (chuva, vento, insolação), erosão } \\
\text { hídrica e superficial. Desertificação e desertização }{ }^{3} .\end{array}$ \\
\hline Recursos Hídricos & Diminuição das chuvas e aumento na evaporação da água, assoreamento de cursos de água. \\
\hline
\end{tabular}

Fonte: A autora (2012).

\footnotetext{
${ }^{3}$ Fenômenos socioeconômicos de crescente abandono de um território, província ou região, pela população que o habita, dando como resultado baixas densidades demográficas (PEREIRA; ALMEIDA, 2011, p. 4).
} 
Os impactos provocados por esse modelo extrativista agride os recursos naturais da Caatinga. Mesmo com o avanço das leis ambientais, da rigorosidade, esta em muitos casos é descumprida. No entanto ainda há muito a ser feito para que a natureza seja preservada como assegura o artigo 225, caput, da Constituição Federal/88, diz que: "Todos têm direito ao meio ambiente ecologicamente equilibrado, bem de uso comum do povo e essencial à sadia qualidade de vida, impondo-se ao poder público e à coletividade o dever de defendê-lo e preservá-lo para as presentes e futuras gerações" (SIQUEIRA, 2008, p. 3).

Percebe-se que o desmatamento na região Nordeste é um problema e que essa região tem grande probabilidade de se tornar futuramente em área desértica. O desmatamento acelera esse processo, pois uma vez iniciado aumenta essas chances. Em muitas áreas do município o processo de desertificação já teve início, no entanto, os agricultores não tem conhecimento de tal fenômeno, pois desconhecem os sinais da desertificação. São muitas as áreas afetadas distribuídas em diferentes locais, compactadas e que não produzem quase nada, isso faz com que seja necessário a reposição de húmus e fertilizantes para que o solo volte a produzir. Devido à degradação que atinge o Bioma Caatinga, a preservação se faz necessária, pois esse tipo de vegetação só existe no Nordeste do Brasil.

\subsubsection{Queimadas}

A utilização do fogo é uma prática mecânica que auxilia o homem do campo na limpeza das áreas de produção, entretanto, a má utilização desse recurso causa sérios danos à estrutura do solo, a fauna, a flora e a micro-fauna existente no solo. Dessa forma, "a origem das queimadas é essencialmente agrícola e, em geral, elas ocorrem em áreas já desmatadas, apresentando padrões espaciais diferenciados e uma dinâmica temporal variável" (MIRANDA; CAPUTI; PANIAGO, 2001, p. 7), são realizadas principalmente no período que antecede o preparo do solo, ou seja, após o desmatamento ou as brocas.

Entretanto, "existem muitos 'tipos' de queimadas, cujo impacto ambiental é diferenciado já que estão associadas a diversos sistemas de produção, em situações geográficas variadas" (MIRANDA; CAPUTI; PANIAGO, 2001, p. 7).

No município as brocas e queimadas são realizadas com a finalidade de eliminar a vegetação que tende a crescer na área agrícola. Sendo essa prática realizada pela maioria dos agricultores (Figura 10).

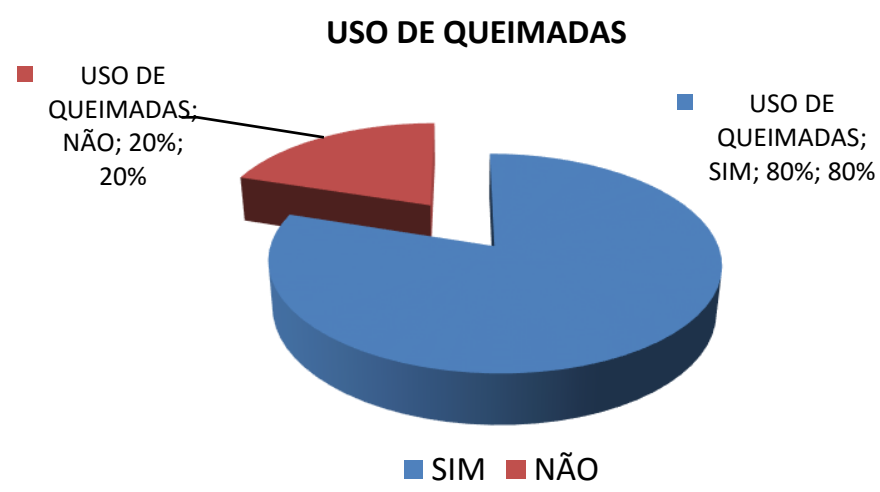

Figura 10 - Agricultores que realizam as queimadas nas áreas pesquisadas.

Fonte: A autora (2012). 
Entre os entrevistados $80 \%$ afirmaram que realizam as queimadas e somente uma pequena parcela cerca de $20 \%$ afirmaram não praticar essa atividade. No entanto, fazer a queima do roçado é uma prática comum dos agricultores no período que antecede o preparo do solo, a queima é realizada durante o dia aumentando a sensação térmica do ar (Figuras 11 e 12).
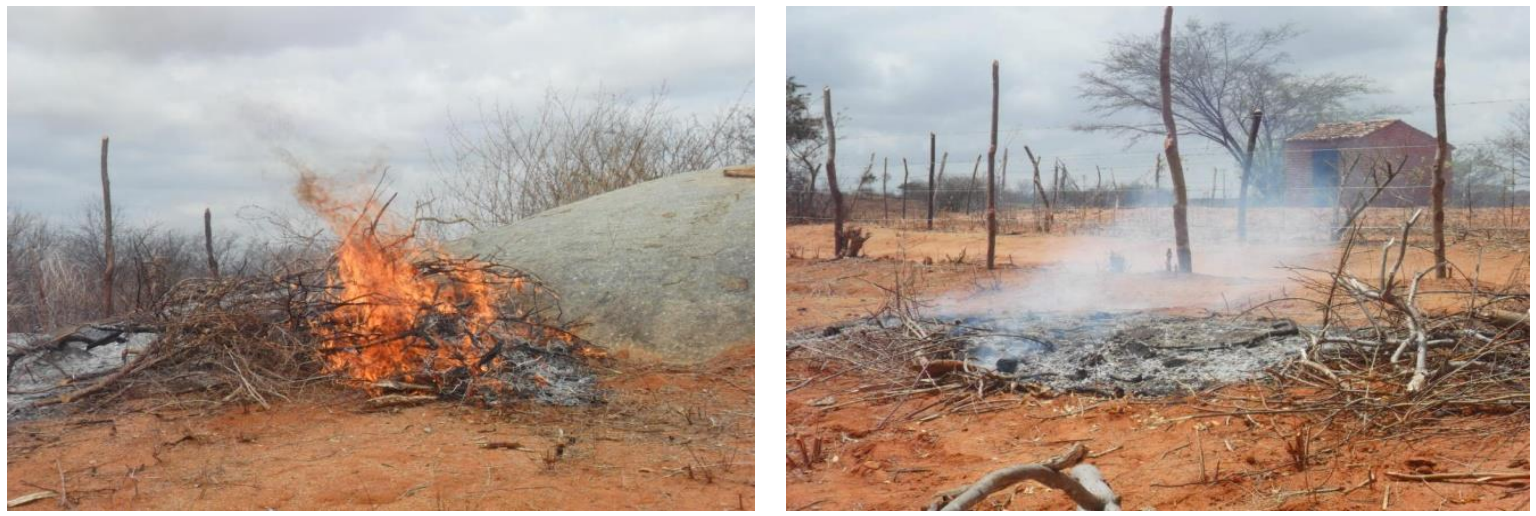

Figuras 11 e 12 - Respectivamente: Queimadas realizadas durante o dia, no município de Tavares-PB. Fonte: Arquivo da pesquisadora (2012).

Com as queimadas o solo fica desprotegido, uma vez que a vegetação o protege do impacto das chuvas, do vento e da erosão. As queimadas são responsáveis pela emissão de milhões de toneladas de nitrogênio para a atmosfera. Esta é uma técnica bastante nociva para os ecossistemas, pois causa um grande desequilíbrio ambiental.

Essa prática contribui com a redução da biodiversidade da Caatinga afetando também os recursos hídricos que são escassos. Além disso, ocasiona a perda de nutrientes existentes no solo, deixando-os esterilizados, exterminando a fauna e a flora presente no solo, elementos que contribuem para a aeração e também para a infiltração da água das chuvas (Figura 13).

Neste mesmo sentido as queimadas provocam desequilíbrio no ecossistema, morte dos microrganismos presentes no solo, poluição do ar, destruição da fauna e da flora e o empobrecimento do solo (Figura 14).
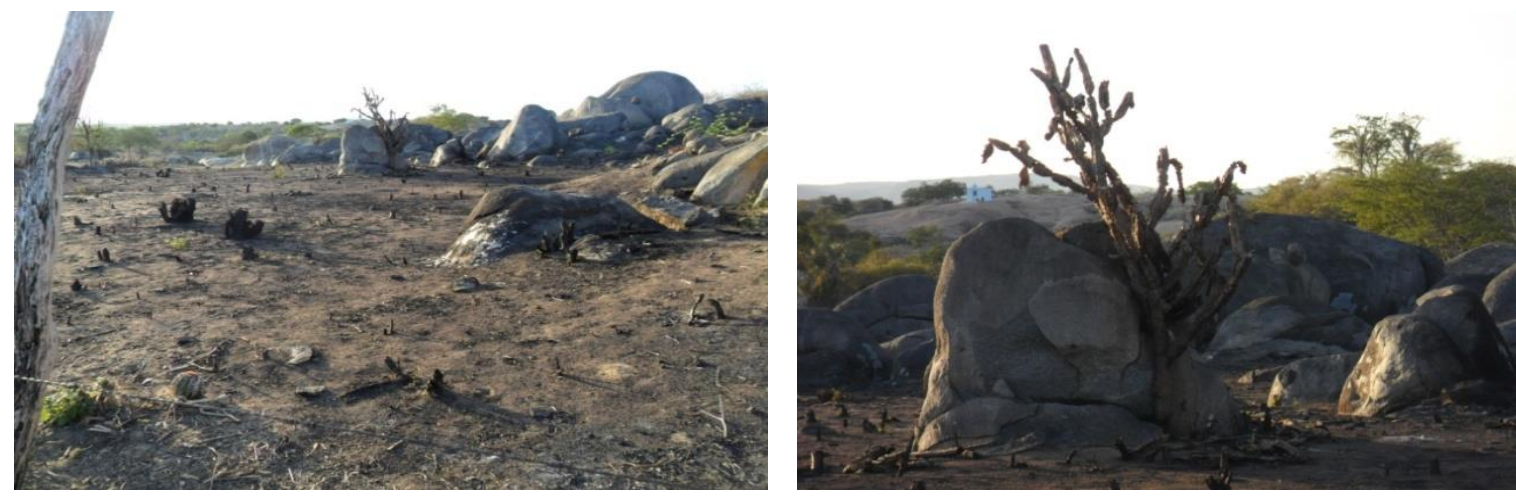

Figuras 13 e 14 - Respectivamente: Solo após a queima e vegetação típica da Caatinga queimada. Fonte: Arquivo da pesquisadora (2011).

Com as queimadas a vegetação desaparece deixando exposta a camada superficial do solo, este sofre dilatações e contrações. Esse processo faz com que o solo se degrade com o tempo, devido à ação da água das chuvas, do aquecimento solar e da ação dos ventos.

A matéria orgânica quando queimada (Figura 15), os nutrientes são dissolvidos com facilidade pela água infiltrada no solo, esses são carregados para o subsolo, local que as raízes das 
plantas temporárias como o milho e o feijão não alcançam, dificultando o crescimento. Neste sentido "o húmus é o principal fator existente no solo para 'prender' os elementos nutritivos, sejam esses do próprio solo, ou colocados, como é o caso dos fertilizantes, evitando que as águas das chuvas dissolvam e os carreguem para fora do alcance das raízes das plantas" (DIRANI, 1988, p. 51).

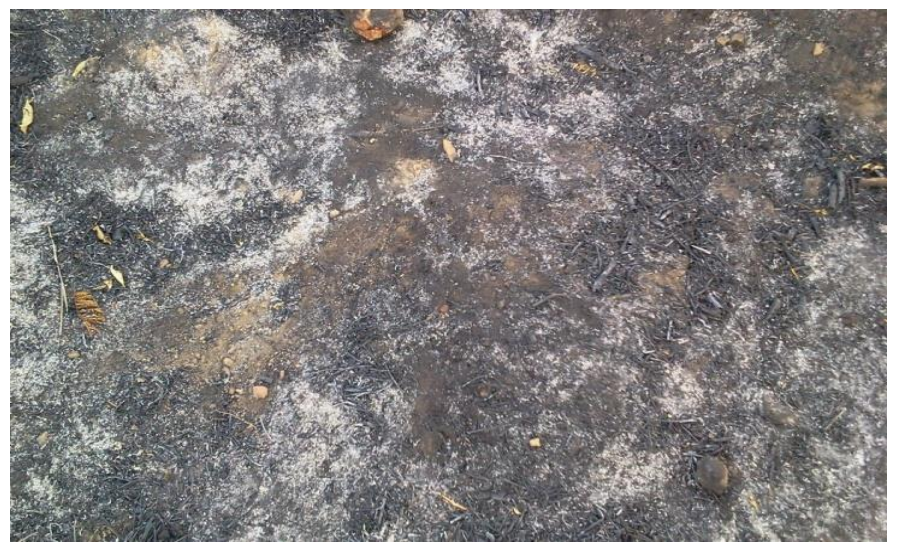

Figura 15 - Solo após a queima, susceptível a ação do clima. Fonte: Arquivo da pesquisadora (2012).

A queimada é uma prática que a curto prazo traz benefícios, entretanto, provoca danos ao meio ambiente. Dentre os muitos impactos provocados pelas queimadas sobre o meio ambiente destacam-se a "poluição, problemas na saúde, prejuízos em redes de eletrificação e em cercas, e queima de áreas não previstas, devido ao fogo fora de controle, causando enormes prejuízos a vizinhos e reservas ecológicas" (EMBRAPA, 2000b, p. 1). Adotar técnicas que reduzam e diminuam os impactos provocados pelas queimadas é fundamental, bem como o controle do fogo.

\subsubsection{Preparo do Solo}

Segundo Ramos (2006, p. 1) "a agricultura tradicional caracteriza-se por um conjunto de técnicas de cultivo que é utilizada, ao longo do tempo, pelas pequenas propriedades ou comunidades agrícolas, destacando-se o uso de sementes próprias resultante da seleção dos próprios agricultores [...]". Aos poucos os agricultores adicionam a atividade tecnologias que facilitam o preparo do solo, entretanto, provocam impactos que associados às técnicas utilizadas, agravam o problema.

As técnicas agrícolas usadas pelos agricultores passam de geração para geração, estas “[...] caracterizam-se pela utilização intensiva dos recursos ou do ambiente natural e da presença constante dos agricultores que manejam os seus recursos genéticos" (RAMOS, 2006, p. 1), ou seja, as sementes utilizadas no plantio.

Dentre os entrevistados $57 \%$ responderam que utilizam o preparo convencional do solo, nesse caso os agricultores usam o arado e o trator para revolver o solo. Outra forma de preparo muito usado pelos agricultores é o plantio semi direto cerca de $43 \%$ dos entrevistados afirmaram que utilizam a enxada e a máquina manual para realizar o plantio em locais não apropriados para a aração como serrotes e topos de serra (Figura 16). 


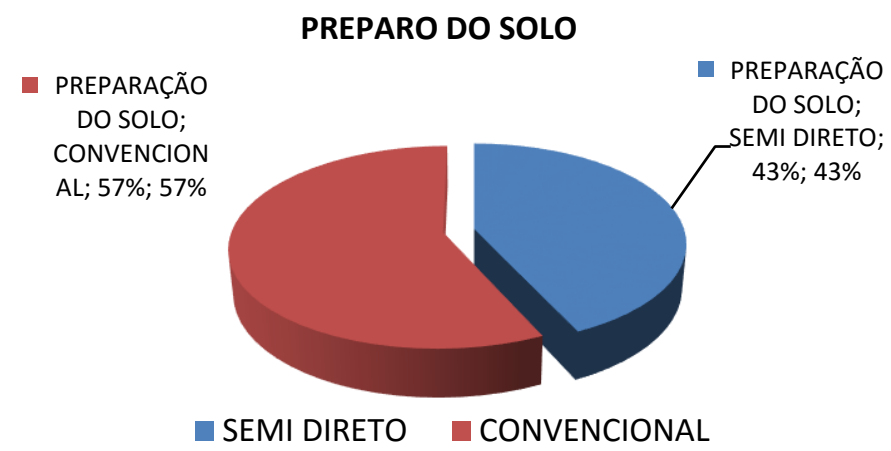

Figura 16 - Formas de preparo do solo mais utilizadas pelos agricultores entrevistados. Fonte: A autora (2012).

No município a agricultura de sequeiro é praticada pelos agricultores que utilizam pequenas áreas para o plantio, onde o preparo do solo é realizado através da aração, essa é uma técnica muito utilizada pelos agricultores que usam o arado (tração animal) para realizar o revolvimento do solo (Figuras 17 e 18). Após o processo de aração os agricultores realizam a planta sem o nivelamento do solo. Sendo este um processo que desnivela o solo, deixando a superfície irregular.
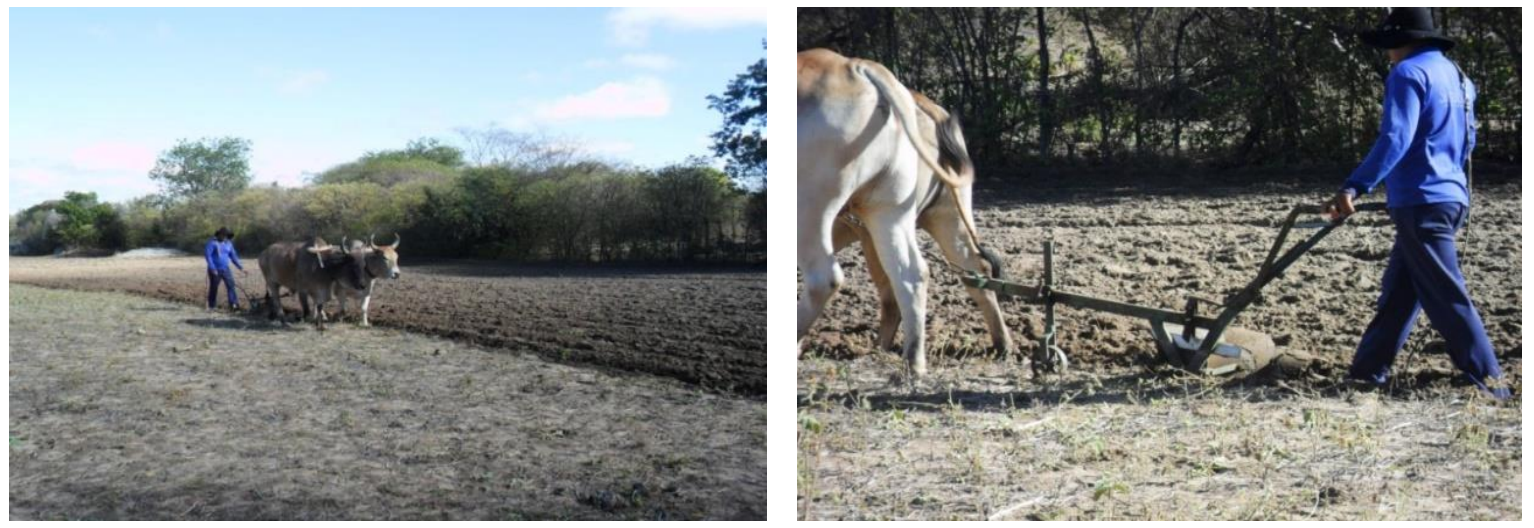

Figuras 17 e 18 - Respectivamente: Processo de aração do solo e corte da terra em fatias (leivas). Fonte: Arquivo da pesquisadora (2012).

A compactação do solo é intensa nessa região, devido à prática da agropecuária. Neste sentido "o revolvimento da camada superficial do solo [...] objetiva corrigir a sua estrutura, que se apresenta na maioria das vezes compactada para o cultivo [...]" (FIRME et al., 1998). Esse processo revolve o solo, cortando a terra em fatias denominadas de leivas, aterrando as ervas daninha e facilitando o crescimento das plantas, sendo este realizado com o arado (tração animal).

Com o revolvimento o solo fica vulnerável a erosões, devido às alterações ocorridas pela desagregação e dispersão da argila que retém grande quantidade de nutrientes necessários para o desenvolvimento das plantas (Figura 19). Esse processo facilita a erosão e a evaporação da água armazenada no solo uma vez que a superfície fica exposta a ação dos raios solares, do vento e das chuvas (Figura 20). 

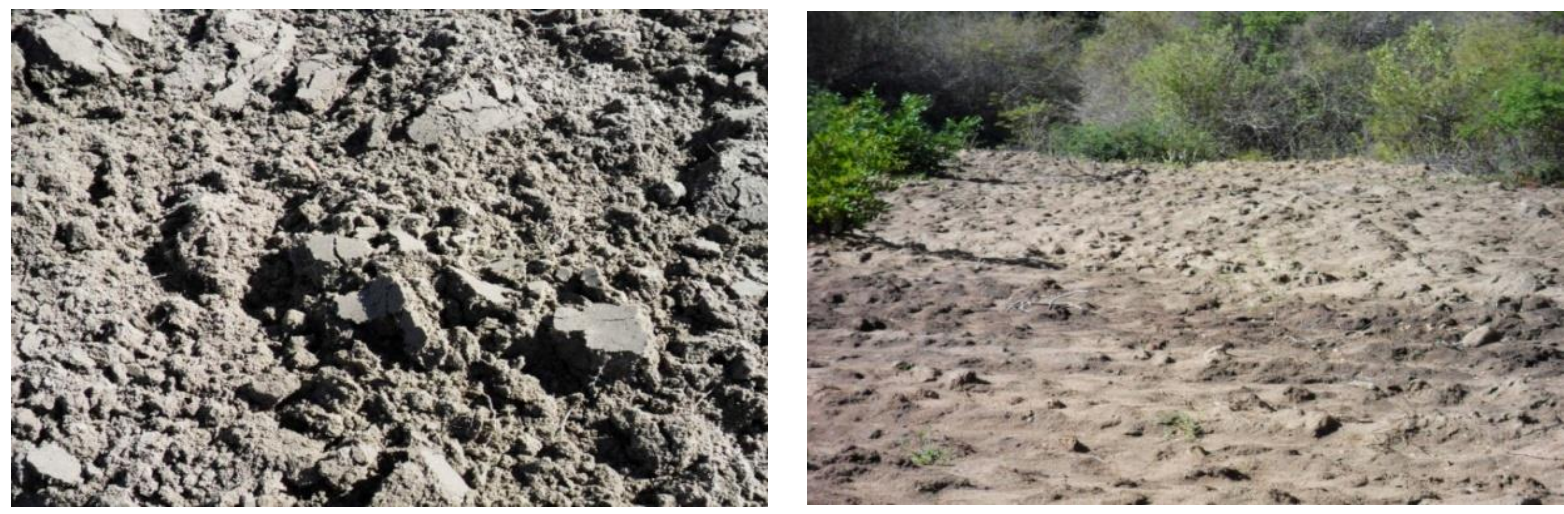

Figuras 19 e 20 - Respectivamente: Solo revolvido e solo exposto à ação da chuva. Fonte: Arquivo da pesquisadora (2012).

"A resultante do antropismo é principalmente a erosão, particularmente, a laminar" (com eventuais ocorrências de pequenas áreas afetadas pela erosão de sulco ou "voçorocas") e os processos de salinização do solo, tanto em áreas de agricultura de sequeiro como irrigadas" (LIMA et al., 2004a, p. 33). As chuvas contribuem para a formação da erosão principalmente no período em que o solo está sendo preparado para o cultivo, que geralmente é na época em que ocorrem as chuvas com maior intensidade provocando com isso a erosão (Figuras 21 e 22).
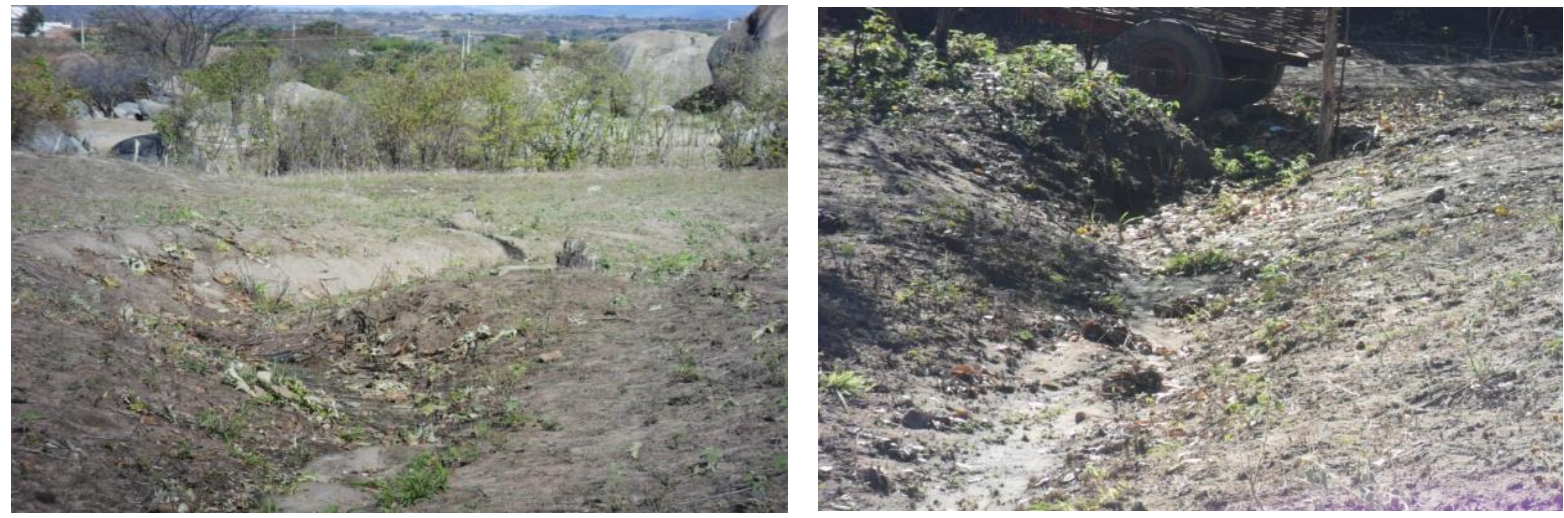

Figuras 21 e 22 - Respectivamente: erosão em terra cultivada anualmente e Sulcos. Fonte: Arquivo da pesquisadora (2012).

Esse processo é resultado das atividades humanas que provocam danos ao meio ambiente principalmente as atividades agrícolas, onde estas são intensificadas pela ação do clima, dessa forma, esse processo é provocado pela ação antrópica e não pelos fatores climáticos, sendo que estes apenas o intensificam.

\section{CONSIDERAÇÕES FINAIS}

As técnicas agrícolas empregadas pelos agricultores são causadoras dos atuais níveis de degradação ambiental existente, não deixando nenhuma dúvida. Neste sentido dentre as principais técnicas utilizadas que foram observadas destacam-se: as queimadas, o desmatamento e o preparo indevido do solo que impacta o meio ambiente, sendo que estas práticas culturais são usadas de forma inadequada na agricultura e promove desequilíbrio e degradação ambiental.

As técnicas agrícolas equivocadas agravam os problemas ambientais na área municipal,

\footnotetext{
${ }^{4}$ Erosão provocada pela ação das águas das chuvas que consiste na remoção da camada superficial do solo.
} 
tornando os solos mais vulneráveis ao processo erosivo e a desertificação, promovendo o esgotando dos mesmos, que ficam exaustos com a prática da agricultura e da pecuária, provocando ainda a compactação do solo pelo pisoteio dos animais e pela ausência das práticas sustentáveis. Ao considerar o problema com a exposição do solo a ação dos raios solares, a erosão hídrica e superficial, lixiviação, redução da vegetação primaria, esterilização devido às queimadas, dá-se para compreender que paulatinamente se perde a qualidade e sustentabilidade dos ecossistemas da caatinga, notadamente pela falta de sensibilidade e conhecimento dos agentes produtivos que lidam com a lavoura do feijão no município.

Dessa forma a qualidade do solo e o equilíbrio dos ecossistemas são alterados pela a ação antrópica negativa que é intensa nessa região. Essa atividade faz parte da tradição regional, sendo passadas de geração para geração, dando continuidade à degradação. Portanto, se faz necessária uma mudança de atos por parte dos agricultores e isso só ocorrerá quando houver mudança no comportamento e atitudes das pessoas em geral e especialmente dos agricultores para que essa triste realidade seja modificada. É preciso que haja uma transformação do homem que lida com o campo, para alcançarmos resultados mais exitosos.

Com isso são necessários estudos mais detalhados sobre o Sertão Paraibano e o município de Tavares sobre a degradação ambiental e a recuperação de áreas degradadas, que proporcionará subsídios para futuros estudos, contribuindo para o conhecimento.

Esse trabalho aponta uma série de problemas de ordem ambiental, que são gerados pela despreocupação dos produtores com a sustentabilidade. Portanto é preciso informar para todos as saídas para esses problemas, através da utilização de práticas agroecológicas, a exemplo do tempo de pousio, da rotação de culturas, da gestão dos recursos hídricos, do uso controlado do fogo como prática mecânica, da utilização de produtos alternativos no combate as pragas e doenças, da adubação orgânica e química com receituário agronômico. Entretanto, a mudança começa nas atitudes de cada pessoa e ser responsável é obrigação de todos.

\section{REFERÊNCIAS}

1. ALENCAR, Ane et al. Desmatamento na Amazônica: indo além da "emergência crônica", [S. I.; s.n], 2004. Disponível em: <http://www.ipam.org.br/download/livro/Desmatamento-naAmazonia-Indo-Alem-da-Emergencia-Cronica-/319>. Acesso em: 05 mar. 2012.

2. AZEVEDO, Andréa Aguiar. MONTEIRO, Jorge Luis Gomes. Análise dos impactos ambientais da atividade agropecuária no cerrado e suas inter-relações com os recursos hídricos na região do Pantanal. [S. I.; s.n], 2002-2003. Disponível em: <http://www.wwf.org.br/informa coes/bliblioteca/?3000>. Acesso em: 03 fev. 2012.

3. BELTRÃO, Breno Augusto et al. (Org.). Projeto cadastro de fontes de abastecimento por água subterrânea no Estado da Paraíba. Diagnóstico do município de Tavares, Estado da Paraíba. Recife - PE: CPRM/PRODEEM, 2005.

4. Companhia Nacional de Abastecimento (CONAB). Área plantada por hectare e produtividade. Fonte: EMATER-PB, Regional de Princesa Isabel, 2011.

5. CUNHA, Simone Alves da. Desmatamento e degradação do solo. Projeto Água e Cidadania na Bacia do Apa - Uma abordagem sistemática e transfronteiriça na Década Brasileira da Água CT- HIDRO/MCT/CNPQ. 2007. Disponível em: <http://www.planetaead.com.br/pena 
agua/apoio_didatico/artigos/ArtigoDesmatamento_Simone.pdf> Acesso em: 18 agost. 2012.

6. DIRANI, Ademar. Férias na Fazenda Ecológica. $1^{\circ}$ reimpressão. Goiânia: Cegraf / UFG, 1988, p. 49-51.

7. DRUMOND, Marcos Antônio (Coord.) et al. Avaliação e identificação de ações prioritárias para a conservação, utilização sustentável e repartição de benefícios da biodiversidade do bioma caatinga: estratégias para o uso sustentável da biodiversidade da caatinga. PetrolinaPE: [s.n], 2000.

8. EMBRAPA. Tecnologias para reduzir a prática das queimadas. In: Embrapa: sistemas de produção. 1. Versão eletrônica, dez. 2000. Disponível em: <http://www.preve qmd.cnpm.embrapa.br/cartilha.htm> Acesso em: 24 ago. 2012.

9. FIRME, Deuseles João et al. Preparo de solos em áreas acidentadas. In: Instituto de Pesquisas e Estudos Florestais- IPEF. Circular Técnica n 159, ISSN 0100-3453, 1988.

10. FIRMINO, Rafaelle Gomes; FONSECA, Márcia Batista da. Uma Visão Econômica dos Impactos Ambientais causados pela Expansão da Agricultura. In: Encontro de Extensão 10. UFPB-PRAC, 2008.

11. Instituto Brasileiro de Geografia e Estatística (IBGE). IBGE: Cidades@: Tavares-PB. Disponível em: <http://www.ibge.gov.br/cidadesat/painel/painel.php?codmun=251660>. Acesso em 19 jun. 2012.

12. JUSBRASIL. Artigo 45 da Lei de Crimes Ambientais - Lei 9605/98. Disponível em: <http://www.jusbrasil.com.br/legislacao/busca?q=artigo+45+da+Lei+9.605\%2F98+\&s=legisla cao>. Acesso em 24 jun. 2012.

13. LEPSCH, Igo F. Solos - Formação e Conservação. $3^{\circ}$ ed. Comp. Melhoramento de papel, São Paulo: [s.n], 1976.

14. LIMA, José Roberto de Lima et al., (Coord.). Programa de ação nacional de combate à desertificação e mitigação dos efeitos da seca - PAN BRASIL. Brasília - DF: Ministério do Meio Ambiente / Secretaria de Recursos Hídricos, 2004.

15. MIRANDA, Evaristo Eduardo de; CAPUTI, Eduardo; PANIAGO, Carlos Fernando Assis. Relatório do monitoramento orbital de queimadas no Brasil - 2001. Campinas: Embrapa Monitoramento por Satélite, 2001. 119p., il, mapas.

16. RAMOS, Samírames Rabelo Ramalho. A agricultura tradicional e a preservação da diversidade genética das espécies cultivadas. In: Agroline. 2006. Disponível em: <http://w ww.agronline.com.br/artigos/artigo.php?id=308>. Acesso em: 28 ago. 2012.

17. SABOYA, Rita de Cássia Cunha. Identificação de Solos e Paisagem do Assentamento Vale Verde, Gurupi, TO, para fins de Aptidão agrícola. In: Boletim de Pesquisa e Desenvolvimento 227. Planaltina-DF: Embrapa Cerrados, Nov. 2008, ISSN 1676-918X.

18. SÁNCHEZ, Luis Enrique. Recuperação de Áreas Degradadas: Um campo multidisciplinar de pesquisas. In: Seminário Unesp. Rio Claro, 2006.

19. SIQUEIRA, Flávio Augusto Maretti. Direito Ambiental Penal: Aspectos relevantes da lei 9605/98. In: Salão de Iniciação Cientifica, PUCRS, 2008.

20. SILVA, Dalva Damiana Estevam da. Avaliação da degradação ambiental a partir da prática da cultura do feijão no município de Tavares - PB. 70f. Monografia (Tecnologia em Gestão 
Ambiental) - Instituto Federal de Tecnologia e Ciência da Paraíba - PB, 2012.

21. THIOLLENT, Michel. Crítica metodológica, investigação social e enquete operária. São Paulo: Polis, 1982. 270 p. 